Gut, 1975, 16, 443-453

\title{
The intrinsic innervation of the human alimentary tract and its relation to function
}

\author{
ALAN BENNETT AND HELEN L. STOCKLEY \\ From the Department of Surgery, King's College Hospital Medical School, London
}

SUMMARY The intrinsic innervation of the human gut has been studied in strips of circular and longitudinal muscle removed at operation. Electrical stimulation of the nerves at a wide range of frequencies $(0 \cdot 1$ to $128 \mathrm{~Hz})$ can evoke a variety of responses due to activation of four types of nerves. There is evidence for cholinergic, adrenergic, non-adrenergic inhibitory, and non-cholinergic excitatory fibres, which may be stimulated at different frequencies. The various regions of the alimentary tract, and even the muscle layers within a region, may respond differently to nerve stimulation. This is most marked at $4 \mathrm{~Hz}$ and the observed differences correlate with the function of each part and its dependence on extrinsic innervation. The stomach is relatively insensitive to electrical stimulation, and this is consistent with its reliance on vagal innervation. The dominant excitatory responses in the longitudinal muscle of the oesophagus and ileum correlate with their high motility and propulsive function, whereas the dominant inhibitory responses in the colon correlate with its lower motility and storage function.

Studies using drugs to stimulate the nerves within strips of human gut muscles have indicated marked regional differences in innervation (Bennett and Whitney, 1966a; Bennett, 1968; Bennett, 1970). It is of particular interest that these differences seem to correlate with regional functions and the dependence on extrinsic innervation. The drugs used were ganglion stimulants such as nicotine, which are thought to cause contraction of gut muscle by exciting cholinergic nerves and relaxation by stimulating adrenergic nerves. In brief, the experiments have indicated weak cholinergic and adrenergic intrinsic activity in human stomach (Bennett and Whitney, 1966b), suggesting a dependence of gastric motility on extrinsic (vagal) innervation. In the highly motile jejunum the intrinsic cholinergic activity overshadows the adrenergic activity (Whitney, 1965), whereas the reverse is true in the less motile colon (Fishlock and Parks, 1963a, 1966; Bucknell and Whitney, 1964), and the terminal ileum shows an intermediate picture (Bennett, 1965). The importance of these implications makes it necessary to verify and extend the results by different methods. Since drugs might not stimulate all the nerves present, and they may produce effects unrelated to nerve activation, experiments have been made with

Received for publication 21 April 1975. electrical stimulation of strips of human oesophagus, stomach, ileum and colon. Some of these results have already formed the basis of a brief communication (Bennett and Stockley, 1973a), but none of those described in detail have been presented fully elsewhere.

\section{Methods}

Specimens from various regions of the human alimentary canal, which were free from any macroscopically visible lesions, were obtained from the operating theatre as soon as possible after surgical removal. The operations were usually carried out after premedication with Omnopon-Scopolamine (Roche), anaesthesia with fluothane, and muscle relaxation with d-tubocurarine, although other drugs were sometimes used. These included atropine, hyoscine, pethidine, diazepam, thiopentone, Althesin (Glaxo), ketamine, suxamethonium and pancuronium. As discussed previously (Fishlock and Parks, 1963b), no effects of drugs used in surgery have been demonstrated in the gut specimens excised. The specimens were placed in Krebs solution and studied immediately or stored at $4^{\circ} \mathrm{C}$ for up to 24 hours; during this time there is no noticeable change in response. The tissue was laid flat in Krebs solution and the mesentery, mucosa and 
submucosa were cut away with scissors. Strips, $1-2 \mathrm{~mm} \times 1.5-3 \mathrm{~cm}$, were cut through the muscle coat parallel to either the circular or longitudinal muscle fibres. The strips were set up (under a load of $0.5,1$ or $1.5 \mathrm{~g}$ ) in isolated organ baths (Bennett, 1964), containing Krebs solution at $37^{\circ} \mathrm{C}$ bubbled with $5 \% \mathrm{CO}_{2}$ in $\mathrm{O}_{2}$. Responses, magnified eight or tenfold, were registered on pen recorders using isotonic transducers.

Square-wave pulses of alternating polarity were generated by linked stimulators (Scientific and Research Instrurnents Ltd, nos. 6051 and 6053), and impulse trains of $5,10,20$ or $30 \mathrm{~s}$ were delivered through automatic electric clocks every two to five minutes depending on train duration. A platinum wire electrode at the top of the organ bath delivered alternating positive and negative pulses and another platinum wire below the tissue was the neutral electrode. The applied potential difference of $20 \mathrm{~V}$ (as measured in Krebs solution) gave a voltage drop of $3.4 \mathrm{~V} / \mathrm{cm}$ between the electrodes. In most experiments, the pulse width employed was $1 \mathrm{~ms}$, but $2 \mathrm{~ms}$ was often required to elicit substantial responses in stomach strips. Statistical analysis of results has been made using Student's $t$ test for unpaired data.

\section{DRUGS}

Acetylcholine perchlorate (ACh), adenosine 5'triphosphate (ATP), ( \pm )atropine sulphate, angiotensin II, barium chloride $\left(\mathrm{BaCl}_{2}\right)$, guanethidine sulphate, hexamethonium bromide, Hydergine, 5-hydroxytryptamine creatinine sulphate (5-HT), (-)hyoscine hydrobromide, ( \pm )isoprenaline sulphate, mipafox, methysergide bimaleate, nicotine acid tartrate, (-)noradrenaline bitartrate, oxprenolol hydrochloride, physostigmine sulphate, potassium chloride $(\mathrm{KCl})$, pronethalol hydrochloride, prostaglandin $\mathrm{E}_{2}\left(\mathrm{PGE}_{2}\right)$, quinidine sulphate, and tetrodotoxin (TTX). Concentrations are expressed in terms of free base or acid except for ATP, $\mathrm{BaCl}_{2}$, and $\mathrm{KCl}$.

KREBS SOLUTION (G/L)

$\mathrm{NaCl}, 7 \cdot 1 ; \mathrm{CaCl}_{2} .6 \mathrm{H}_{2} \mathrm{O}, 0.55 ; \mathrm{KH}_{2} \mathrm{PO}_{4}, 0 \cdot 16$; $\mathrm{KCl}, 0.35 ; \mathrm{MgSO}_{4} .7 \mathrm{H}_{2} \mathrm{O}, 0.29 ; \mathrm{NaHCO}_{3}, 2 \cdot 1$; dextrose, $1 \cdot 0$.

\section{Results}

RESPONSES TO ELECTRICAL STIMULATION The responses are the net effect of stimulating all excitatory and inhibitory nerves present, and in the absence of blocking drugs only the dominant innervation may be apparent. However, the situation is complicated by the fact that different responses may occur at other frequencies, presumably due to variations in nerve sensitivity. As shown later, there were regional differences in response to stimulation over a wide range of frequencies, and these have been analysed pharmacologically. The greatest differences were seen at $4 \mathrm{~Hz}$, and, since this frequency is considered to be within the physiological range (Folkow, 1952; Douglas and Ritchie, 1957), these results have been chosen as the main basis for the subsequent discussion.

\section{Oesophagus}

Specimens of lower oesophageal smooth muscle were obtained from eight patients with obstructions due to carcinoma, and 14 circularly cut strips were studied. Ten strips were also cut parallel to the longitudinal muscle fibres in the five specimens which were large enough. The type of response of the circular muscle to electrical stimulation varied between strips and also with the stimulating frequency as illustrated in figure 1 . At $0 \cdot 1-0.5 \mathrm{~Hz}$ most strips contracted but at $1-4 \mathrm{~Hz}$ the proportion relaxing increased to $46 \%$. The relaxation at all frequencies was followed by a rapid contraction immediately stimulation ceased (the after-contraction). At 8 and $16 \mathrm{~Hz}$ there was slightly less tendency to relax but at 32 and $64 \mathrm{~Hz}$ the proportion of strips inhibited rose to 50 and $75 \%$. At frequencies between those giving pronounced contraction or relaxation, some strips gave a triphasic response of contraction followed by relaxation and an after-contraction.

Seven of the 10 longitudinal muscle strips were predominantly contracted by electrical stimulation

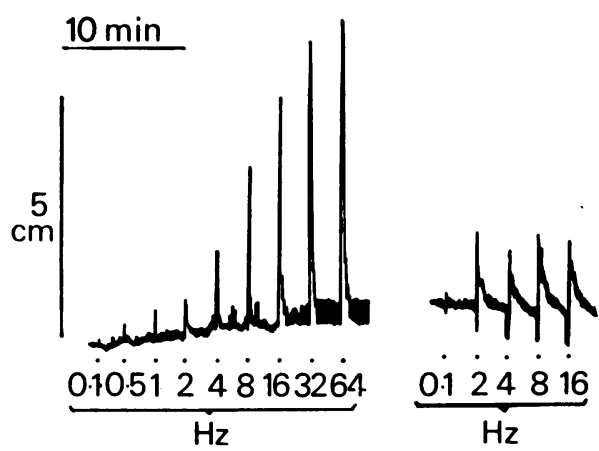

Fig 1 Responses of human distal oesophageal muscle to electrical stimulation (1 ms pulses; $10 \mathrm{~s}$ trains). On the left are responses typical of those seen in longitudinal strips, consisting of contractions which increased as the stimulating frequency was raised. In many circular muscle strips (right hand side) biphasic responses were elicited with a wide range of frequencies, but other circular strips gave responses more like those of the longitudinal muscle. 
(fig 1), although some failed to respond to low frequencies $(0 \cdot 1-1 \mathrm{~Hz})$. None of the longitudinal strips relaxed at $0.1,0.5$ or $64 \mathrm{~Hz}$, and at intermediate frequencies only $17-33 \%$ of the strips responded in this way. The frequency at which most logitudinal strips relaxed $(4 \mathrm{~Hz})$ was also the optimal low frequency for relaxing the circular strips.

\section{Stomach}

Fifty-two specimens of human gastric body and antrum were obtained from surgical resections for gastric or duodenal ulceration or gastric carcinoma. In total, 145 strips were cut parallel to the longitudinal or circular muscle fibres of the body or antrum. Electrical stimulation usually elicited contractions which increased as the stimulating frequency was raised (fig 2). Occasionally there was a small relaxation or a biphasic response consisting of contraction followed by relaxation. The inhibitory responses were elicited mostly from circularly cut antral strips at 1 to $8 \mathrm{~Hz}$. Many of the stomach strips responded weakly to electrical stimulation, and $2 \mathrm{~ms}$ pulses were needed in most cases to evoke contractions with low frequencies. At $1 \mathrm{~ms}$ and $1 \mathrm{~Hz}$ only $30 \%$ of strips contracted, whereas $75 \%$ responded to $2 \mathrm{~ms}$ pulses at the same frequency. At higher frequencies more preparations responded to stimulation with pulses of either duration. As previously

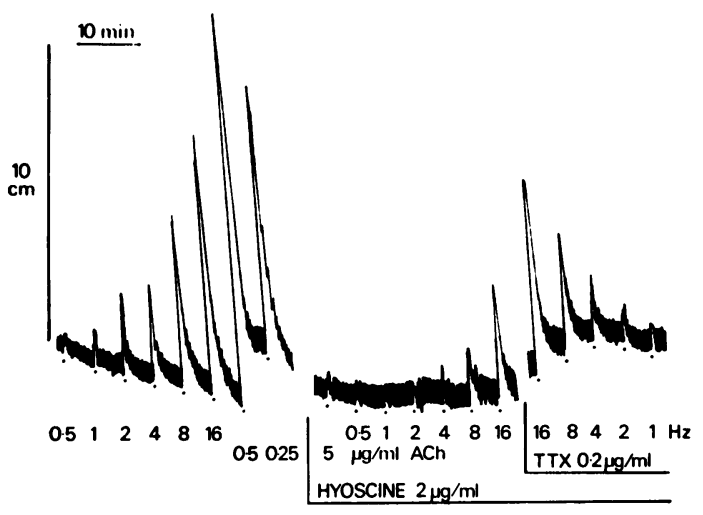

Fig 2 Contractions of longitudinal muscle from human gastric body before and after hyoscine and tetrodotoxin (TTX). Hyoscine prevented contraction to 20 times the control concentration of $A C h$ and prevented or greatly reduced contractions to electrical stimulation ( $2 \mathrm{~ms}$ pulses, $30 \mathrm{~s}$ trains). The small contractions which remained at 4-16 $\mathrm{Hz}$ were also resistant to tetrodotoxin. Since contractions after tetrodotoxin were somewhat larger than in the presence of hyoscine it is possible that inhibitory nerves (which would be unaffected by hyoscine but blocked by tetrodotoxin) were also being activated. reported (Metcalfe and Bennett, 1971), the circular muscle from the gastric body was particularly unresponsive, with only two out of 10 strips contracting at 0.1 to $0.5 \mathrm{~Hz}$. This was significantly less than the proportion of excitable longitudinal preparations of gastric body $(\mathrm{P}<0.05)$.

\section{Ileum}

Specimens of terminal ileum proximal to the ileocaecal sphincter were obtained from 15 patients with cancer of the caecum. Studies were made on 22 circular muscle and 20 longitudinal muscle strips. As in the oesophagus, the types of response varied between strips and also with stimulating frequency (fig 3). Circular muscle usually relaxed during stimulation at $1 \mathrm{~Hz}$ and above, but at 0.1 to $0.5 \mathrm{~Hz}$ almost half of the responding strips contracted. The tendency to relax was maximal at 2 to $4 \mathrm{~Hz}$, and the proportion contracting increased with frequency above this. The relaxation was sometimes followed by an after-contraction similar to that observed in some oesophageal strips. Longitudinal ileal muscle gave predominantly contractile responses at $0 \cdot 1$ to $64 \mathrm{~Hz}$. However, seven of the 20 preparations relaxed at some intermediate frequencies, and this was usually followed by an after-contraction. As in the circular muscle, the tendency to relax was greatest at 2 to $4 \mathrm{~Hz}$.

\section{Colon}

The responses of the sigmoid colon have been described and analysed previously (Stockley and
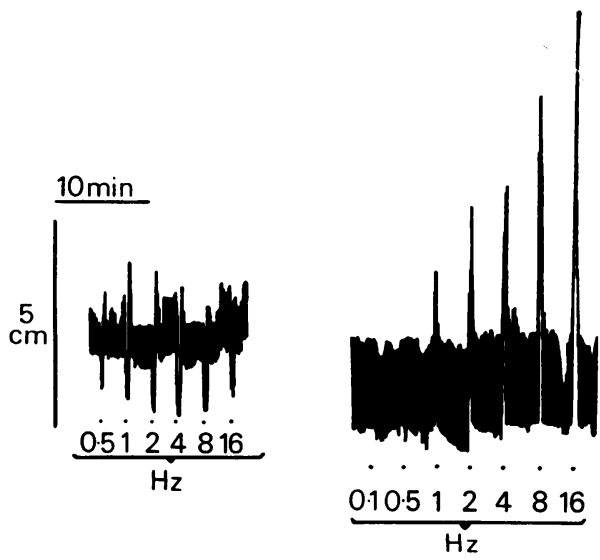

Fig 3 Responses of circular (left) and longitudinal (right) muscle from human terminal ileum to electrical excitation (1 ms pulses; $20 \mathrm{~s}$ trains). The circular muscle responded with relaxation and after-contraction whereas the longitudinal muscle contracted during stimulation at 1 to $16 \mathrm{~Hz}$. Occasionally circular muscle strips also contracted during stimulation (see fig 7). 
Bennett, 1974), but we describe here nine specimens of ascending colon which provided 14 circular and five longitudinal muscle strips. The responses of the taenia strips closely resembled those described by Bucknell $(1965,1966)$, and those cited above in the sigmoid region. The responses of the circular muscle from the ascending and sigmoid colon were also similar to each other in many respects, but at $4 \mathrm{~Hz}$ and above the after-contraction was more pronounced and prolonged in the ascending colon (fig 4).

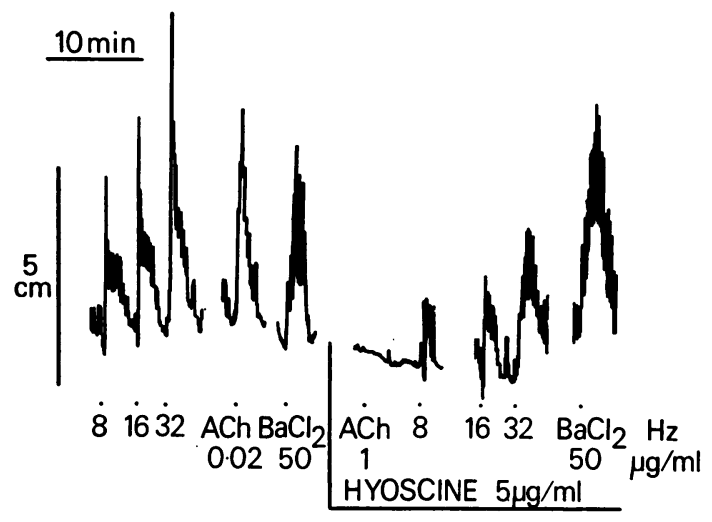

Fig 4 Following an initial small relaxation $(8,16 \mathrm{~Hz})$ or contraction $(32 \mathrm{~Hz} ; 1 \mathrm{~ms}$ pulses, $20 \mathrm{~s}$ trains) human ascending colonic circular muscle gave first a rapid and then a prolonged after-contraction. In the presence of hyoscine, which antagonized contraction to ACh but not to $\mathrm{BaCl}_{2}$, the rapid after-contraction was prevented but the slow component remained.

The proportion of strips from the various regions which contracted or relaxed are compared in figure 5. Responses at $4 \mathrm{~Hz}$ were selected since this frequency is within the physiological range, and here the differences between regions seemed most pronounced. Generally, at higher and lower frequencies more strips contracted. At $4 \mathrm{~Hz}$ in the distal oesophagus, almost half of the circular and about $30 \%$ of the longitudinal strips relaxed. At $4 \mathrm{~Hz}$ a gradient in the rest of the gut, rather similar to that discussed by Bennett and Whitney (1966a), was obtained, although the tendency to contract with ganglion stimulants was less than with electrical stimulation. Of the preparations which responded, all those from the gastric body and most from the antrum contracted. Slightly more than half of the longitudinal ileal strips contracted, whereas $80-100 \%$ of the circular ileal preparations and both muscle layers of the colon relaxed.

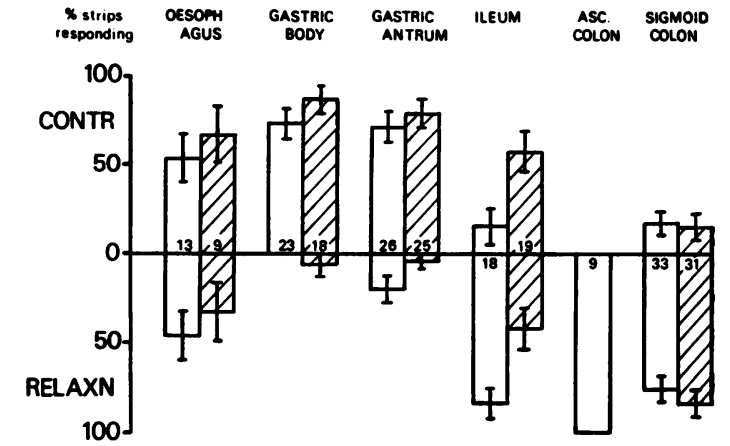

Fig 5 Percentage of circular (open columns) and longitudinal (hatched columns) muscle strips from various parts of the gut contracting or relaxing during electrical stimulation at $4 \mathrm{~Hz}$. The number in each column is the number of strips studied, and the vertical bars represent $\pm 1 S E$ of a percentage. There is a gradual change from contraction of most gastric body specimens to relaxation of most colonic strips. Where contraction + relaxation does not add up to $100 \%$, the remainder of the strips did not respond.

\section{Analysis of the Responses}

The neuronal nature of the response to electrical stimulation was tested with tetrodotoxin which selectively blocks conduction in autonomic nerves (Kao, 1966). Most of the responses were prevented by tetrodotoxin $(0 \cdot 1-1 \mu \mathrm{g} / \mathrm{ml})$ but small contractions persisted in some strips from each region. Similar contractions in guinea-pig ileum seem to be due to direct electrical excitation of the smooth muscle cells, and their magnitude appears to depend on the orientation of the electric current with respect to the muscle fibres (Bennett and Stockley, 1973b; 1974; Stockley, 1974). Only the responses which were sensitive to tetrodotoxin are considered in the following analysis of the nerve-mediated responses.

\section{RESPONSES INVOLVING PREGANGLIONIC NER VES}

The ganglion-blocking drug hexamethonium (10$50 \mu \mathrm{g} / \mathrm{ml}$ ) greatly reduced or prevented contractions or relaxations caused by nicotine. However, electrically induced responses were not affected unless those to $\mathrm{KCl}$ or $\mathrm{BaCl}_{2}$ were also reduced. Thus any reduction of the electrically stimulated response was non-selective, and only postganglionic nerves appeared to be excited. Nevertheless, when ACh breakdown was prevented by physostigmine $(100 \mathrm{ng} /$ $\mathrm{ml}$ ) some electrical stimulation at ganglionic sites was detected. Contractions of three gastric antral strips $(2$ and $4 \mathrm{~Hz}$ ) and two sigmoid colonic circular strips 
(0.1-8 $\mathrm{Hz}$ but not at higher frequencies) were reduced by hexamethonium $(10 \mu \mathrm{g} / \mathrm{ml})$. Similarly, contractions to $\mathrm{ACh}$ were approximately halved by hexamethonium in two of these antral strips treated with physostigmine.

\section{CONTRACTIONS MEDIATED BY}

\section{POSTGANGLIONIC CHOLINERGIC NERVES}

The presence of postganglionic cholinergic nerves was indicated by the increase in electrically induced contractions when breakdown of ACh was prevented by anticholinesterases, and by the decreased contractions with cholinoceptor antagonists (atropine and hyoscine). Contractions of the longitudinal and circular layers to $\mathrm{ACh}$ and electrical stimulation with a wide range of frequencies were enhanced $(25-500 \%)$ by physostigmine $(0 \cdot 1-10 \mu \mathrm{g} / \mathrm{ml})$ in distal oesophageal strips (fig 6), gastric body and antrum, and distal ileum (nine, eight, 16 and six experiments respectively). The anticholinesterase mipafox $(50-200 \mu \mathrm{g} / \mathrm{ml})$ was also studied in 18 gastric strips and produced a similar potentiation. Physostigmine and mipafox acted selectively since in the gastric strips contractions to $\mathrm{KCl}, \mathrm{BaCl}_{2}$ or angiotensin II were mainly unaffected. The potentiation in oesophageal and ileal strips was not analysed quantitatively because inhibitory responses often partly masked the contractions. However, a significant $(\mathbf{P}<0.02)$ increase was found in both circular and longitudinal strips from gastric body and antrum, although the degree of enhancement of contractions varied from only $60 \%$ increase in body longitudinal

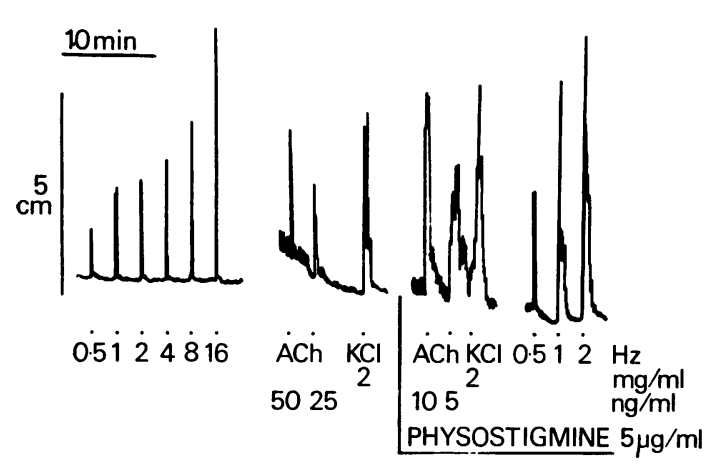

Fig 6 Enhancement by physostigmine of contractions to electrical stimulation (1 ms pulses; $10 \mathrm{~s}$ trains) and $A C h$ in distal oesophageal longitudinal muscle. Responses to ACh were potentiated nearly 10-fold and the contraction to $2 \mathrm{~Hz}$ in the presence of physostigmine was larger than that elicited previously by $16 \mathrm{~Hz}$. Contractions to $\mathrm{KCl}$ were only marginally larger after physostigmine. muscle to $500 \%$ in antral circular muscle. The amount of potentiation did not appear to vary with the frequency of electrical stimulation but was less in the longitudinal strips from both gastric regions than in respective circular strips $(P<0.05$ antrum; $P<0.025$ body). In contrast, the contractions to ACh tended to be potentiated more in the longitudinal (about $500 \%$ ) than the circular preparations ( 210 to $260 \%)(P<0.005)$. It should be pointed out, however, that in a few cases physostigmine increased the tone of the tissue so much that further contraction was not possible.

Blockade of cholinoceptors with atropine or hyoscine $(0 \cdot 1$ to $10 \mu \mathrm{g} / \mathrm{ml})$ strongly antagonized the contractions to ACh and to electrical stimulation in the longitudinal and circular muscle strips (distal oesophagus; gastric body, fig 2, and antrum; distal ileum, fig 7; and ascending and descending colon; 13, 17, 24, 14, nine and 18 experiments respectively). In addition, there were two types of neurogenic contraction which were not prevented by hyoscine. These will be discussed later. The contractions were replaced by relaxations frequently in strips of oesphagus, ileum and colon, occasionally in gastric antral muscle and rarely in gastric body. In the stomach, the tendency of atropine or hyoscine to reduce contractions was less in the longitudinal muscle than in the circular muscle but this difference reached statistical significance $(P<0.02)$ only in the gastric body at $16 \mathrm{~Hz}$.

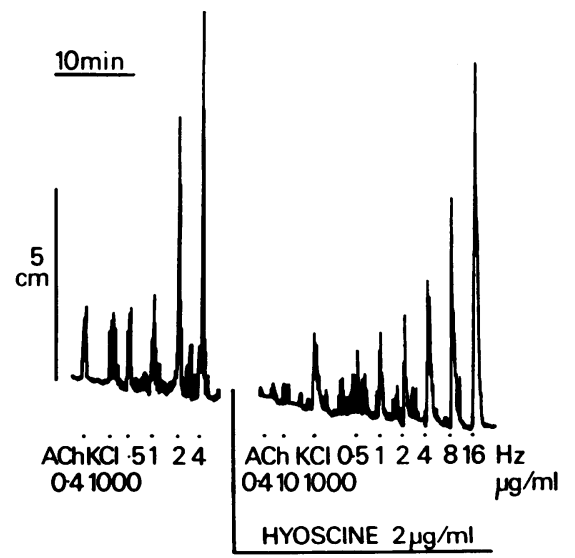

Fig 7 Antagonism by hyoscine of contractions to ACh and electrical stimulation (1 ms pulses; $20 \mathrm{~s}$ trains) in terminal ileal circular muscle. In the presence of hyoscine, contractions to electrical stimulation at $2 \mathrm{~Hz}$ and above were considerably reduced, but responses at lower frequencies, like those to $\mathrm{KCl}$, were little affected. 
CONTRACTIONS MEDIATED BY

POSTGANGLIONIC NON-CHOLINERGIC

NERVES

In 13 out of 25 strips of circular and longitudinal oesophageal and ileal muscle, contractions elicited at frequencies below $1 \mathrm{~Hz}$ were unaltered or only slightly changed by the drugs used to potentiate or block cholinergic contractions (fig 7). Similar responses occurred in circular sigmoid colonic muscle as reported previously (Stockley and Bennett, 1974). Their neurogenic nature was indicated by blockade with tetrodotoxin $(0 \cdot 1-0.5 \mu \mathrm{g} / \mathrm{ml})$, and 5-HT was probably excluded as the transmitter since methysergide $(0.5$ to $10 \mu \mathrm{g} / \mathrm{ml})$ had no obvious effect on the electrically induced responses although contractions to 5-HT were blocked.

\section{AFTER-CONTRACTIONS}

Two types of after-contraction were observed during these experiments. As described above and seen in figs 1,3 and 4 , inhibitory responses to electrical stimulation with a wide range of frequencies were followed by rapid after-contraction in many oesophageal, ileal and colonic strips. Since these contractions were enhanced by physostigmine and reduced by atropine or hyoscine, they seem due partly to stimulation of cholinergic nerves. However, part of the response was resistant to hyoscine in three out of five circular, and five out of eight longitudinal ileal strips, and in all oesophageal and ascending colonic strips tested. These contractions were prevented by quinidine $(50-400 \mu \mathrm{g} / \mathrm{ml}$; used to block nonadrenergic relaxations; Burnstock, Campbell, Satchell, and Smyth, 1970) or by TTX (0.1-1 $\mu \mathrm{g} / \mathrm{ml})$. The preceding inhibition, which may have given rise to the after-contraction, was also prevented.

In ascending colonic circular muscle another slower, more prolonged after-contraction was recorded. Without hyoscine, this was observed only as a prolongation of the rapid after-contraction. Hyoscine $(1-5 \mu \mathrm{g} / \mathrm{ml})$ reduced the rapid aftercontraction so that the slow response, which often started during electrical stimulation, could sometimes be distinguished as a separate peak at 8,16 or $32 \mathrm{~Hz}$ (fig 4). Similar hyoscine-resistant contractions observed at $10-50 \mathrm{~Hz}$ in the longitudinal muscle of the guinea-pig proximal colon were prevented by the adrenergic neurone-blocking drug guanethidine, the $\alpha$-adrenoceptor-blocking drug phentolamine or the 5-HT antagonist methysergide (Costa and Furness, 1972; Furness and Costa, 1973), but these responses of human ascending colonic circular muscle were unaltered by guanethidine $(10-20 \mu \mathrm{g} / \mathrm{ml}$; six experiments), Hydergine (an $\alpha$-adrenoceptor antagonist; $5 \mu \mathrm{g} / \mathrm{ml}$, one experiment) or methysergide (50-100 $\mu \mathrm{g} / \mathrm{ml}$; two experiments).
CONTRACTIONS DUE TO ELECTRICAL

STIMULATION OF THE MUSCLE

Contractions at the lower frequencies appeared to be neurogenic since they were greatly reduced or prevented by tetrodotoxin $(0 \cdot 1-1 \mu \mathrm{g} / \mathrm{ml}, 82$ experiments). However, at higher frequencies (particularly at $16 \mathrm{~Hz}$ and above), there were contractions resistant to both hyoscine and tetrodotoxin. Thus overall in gastric strips at 64 and $128 \mathrm{~Hz}$ the contractions were reduced by only about $25 \%$. These responses were probably due to direct stimulation of the muscle (Bennett and Stockley, 1973b, 1974).

\section{RELAXATIONS MEDIATED BY}

\section{POSTGANGLIONIC NERVES}

The relaxations to electrical stimulation or nicotine seemed to be mediated by nerves, since they were prevented by tetrodotoxin $(0 \cdot 1-0 \cdot 5 \mu \mathrm{g} / \mathrm{ml})$. Both adrenergic and non-adrenergic inhibitory nerves are known to innervate the gut, and the contribution of the former was studied by adrenergic neurone blockade with guanethidine, and $\alpha$ - and $\beta$-adrenoceptor blockade with Hydergine + pronethalol or oxprenolol. These experiments were carried out in the presence of hyoscine $(2-5 \mu \mathrm{g} / \mathrm{ml})$ to block cholinergic excitation, thus unmasking or potentiating the inhibitory responses.

In lower oesophageal circular muscle, guanethidine $(5-10 \mu \mathrm{g} / \mathrm{ml}$; two strips) or oxprenolol $(1 \mu \mathrm{g} / \mathrm{ml}$; two strips) reduced but did not prevent electrically induced inhibition at 1 to $64 \mathrm{~Hz}$. In the longitudinal muscle neither guanethidine $(5 \mu \mathrm{g} / \mathrm{ml}$; two experiments) nor Hydergine $(2 \mu \mathrm{g} / \mathrm{ml})+$ pronethalol $(1 \mu \mathrm{g} / \mathrm{ml})$ (one experiment) decreased the relaxations to electrical stimulation $(1-50 \mathrm{~Hz})$ although the adrenoceptor antagonists prevented relaxation to noradrenaline. Only a few experiments were possible on this tissue because of the relative infrequency of oesophageal resections.

Despite the presence of atropine or hyoscine, stomach strips rarely responded to electrical stimulation with substantial relaxation, even though the tissue possessed tone. Inhibitions which were sufficiently large and reproducible for further study were obtained in only one longitudinal and three circular preparations of gastric body, and seven circular and three longitudinal antral strips. Guanethidine $(10 \mu \mathrm{g} / \mathrm{ml}$; eight experiments) or $\alpha$ - and $\beta$-adrenoceptor blockade (five experiments) failed to reduce the relaxations elicited at 1 to $64 \mathrm{~Hz}$. Relaxations to isoprenaline or noradrenaline (in doses up to 10fold greater than required for control responses), but not ATP $(20-200 \mu \mathrm{g} / \mathrm{ml})$ or $\mathrm{KCl}(1-2.5 \mathrm{mg} / \mathrm{ml})$, were prevented by adrenoceptor blockade. Similarly in the ileum, guanethidine $(10-50 \mu \mathrm{g} / \mathrm{ml}$; fig 8) greatly reduced or prevented relaxations to nicotine, 


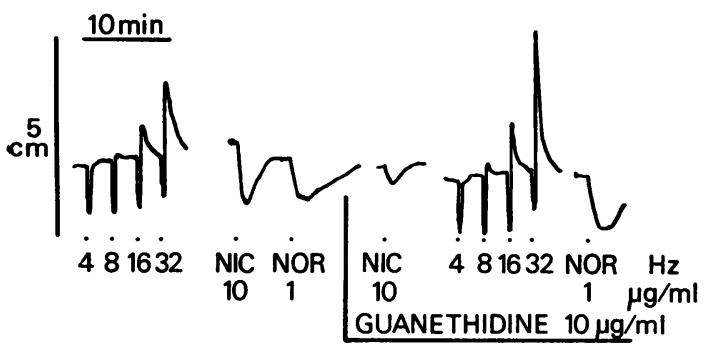

Fig 8 Relaxations of human ileal circular muscle, in the presence of hyoscine $(2 \mu \mathrm{g} / \mathrm{ml})$, to electrical stimulation (1 ms pulses; 20 s trains), nicotine (NIC) and noradrenaline (NOR). Guanethidine greatly decreased the relaxation to nicotine but did not affect relaxations to electrical stimulation or noradrenaline.

but did not alter those to electrical stimulation (0.5$64 \mathrm{~Hz}$ ) in five circular and four longitudinal strips. Furthermore, oxprenolol $(1-5 \mu \mathrm{g} / \mathrm{ml})$ caused no reduction of electrically induced relaxations in six circular and three longitudinal ileal strips although responses to noradrenaline $(0.5-12.5 \mu \mathrm{g} / \mathrm{ml})$ were antagonized.

These electrically induced relaxations which proved resistant to blockade with conventional adrenolytic drugs seem similar to the non-adrenergic inhibitory responses previously described in human colonic muscle (Bucknell, 1965, 1966; Crema, del Tacca, Frigo, and Lecchini, 1968; Burnstock, Satchell, and Smythe, 1972; Stockley and Bennett, 1974). The transmitter of these responses might be ATP or a closely related substance and the nerves have tentatively been designated 'purinergic' (Burnstock et al, 1970; Burnstock, 1972). Relaxations caused by ATP and by non-adrenergic inhibi-

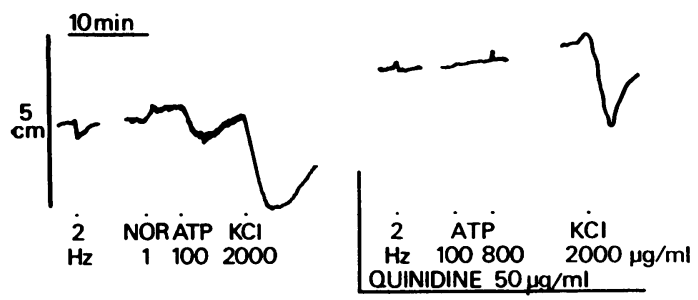

Fig 9 Human gastric antral circular muscle in the presence of hyoscine $(5 \mu \mathrm{g} / \mathrm{ml})$ : electrical stimulation (2 ms pulses; $20 \mathrm{~s}$ trains) and ATP caused relaxations which were antagonized by quinidine $(50 \mu \mathrm{g} / \mathrm{ml})$, but relaxation to $\mathrm{KCl}$ was unaffected. The contraction to noradrenaline (NOR) seen in this strip is consistent with previous observations of $\alpha$-adrenoceptor-mediated excitation in some human gastric strips (Haffner, Liavag, and Setekleiv, 1969). tory nerve stimulation are antagonized by quinidine (Burnstock et al, 1972), so this drug can be used as a tool although it is not very selective. In three gastric antral circular strips, quinidine $(50-200 \mu \mathrm{g} / \mathrm{ml})$ antagonized relaxations to ATP (125 or $250 \mu \mathrm{g} / \mathrm{ml})$ and reduced those elicited by electrical stimulation at 2,4 or $8 \mathrm{~Hz}$ (mean reduction $68 \%$ ). A concentration of $200 \mu \mathrm{g} / \mathrm{ml}$ reduced relaxations to $\mathrm{KCl}$ by $50 \%$ but lower concentrations had no effect (fig 9). In two oesophageal circular strips and five circular and two longitudinal ileal strips quinidine (10$100 \mu \mathrm{g} / \mathrm{ml}$ ) prevented or greatly reduced relaxations and after-contractions at 0.5 to $16 \mathrm{~Hz}$. Relaxations to ATP $(10-500 \mu \mathrm{g} / \mathrm{ml}$; seven experiments) were also antagonized, but so were those to nicotine (12.5 $\mu \mathrm{J} / \mathrm{ml}$; one experiment $) \mathrm{KCl}(2.5 \mathrm{mg} / \mathrm{ml}$; four experiments) and $\mathrm{PGE}_{2}(125 \mathrm{ng} / \mathrm{ml}$; one experiment $)$.

\section{Discussion}

The electrically induced responses of different regions of the human alimentary canal are similar in many ways to those evoked by nerve excitation with ganglion stimulants. The present experiments add to our understanding of the role of the intrinsic nerves in gut motility, and they further the view that regional differences of innervation correlate with motility.

THE INTRINSIC INNERVATION OF DIFFERENT PARTS OF THE ALIMENTARY CANAL

The oesophageal responses to electrical stimulation observed in the present experiments confirm and extend those reported previously. Ganglion stimulants relax the circular muscle of the human distal oesophagus (Ellis, Kauntze, Nightingale, and Trounce, 1960; Misiewicz, Waller, Anthony, and Gummer, 1969); but the longitudinal muscle was reported to contract (Ellis et al, 1960) or relax (Misiewicz et al, 1969). Perhaps different experimental conditions explain this discrepancy. Ellis et al (1960), using electrical stimulation, found that the longitudinal oesophageal muscle receives mainly cholinergic innervation, although relaxations could be produced in the presence of atropine. The circular muscle possessed a predominantly inhibitory innervation which was not analysed further. Our studies show that both layers of oesophageal muscle receive excitatory and inhibitory innervation. Cholinergic excitation generally predominates in the distal longitudinal layer but the main response of the circular muscle varies between excitation and inhibition, depending on factors such as the rate of stimulation. Furthermore, both adrenergic and nonadrenergic pathways contribute to the inhibitory innervation of circular strips, whereas only non- 
adrenergic relaxations were demonstrated in the longitudinal muscle. Thus the intrinsic innervation of the human distal oesophagus seems to resemble that of the opossum which responds to electrical impulses with cholinergic and non-cholinergic contractions, and non-adrenergic relaxations (Lund and Christensen, 1969; Christensen, 1970; Tuch and Cohen, 1973).

Previous observations on the human stomach with ganglion stimulants suggested weak intrinsic cholinergic and adrenergic innervation (Bennett and Whitney, 1966b). Electrical stimulation revealed weak cholinergic contractions which, in the presence of hyoscine, were occasionally converted to nonadrenergic relaxations (Metcalfe and Bennett, 1971). The present results support the conclusion that the contractions at low frequencies are due to stimulation of cholinergic nerves, but the tetrodotoxinresistant contractions at higher frequencies were probably due to direct excitation of the muscle. Perhaps these were more pronounced in gastric strips than in other parts of the gut because longer electrical pulses were needed to stimulate the tissue. Neurogenic non-adrenergic relaxations were seen in only a few gastric strips, and, again in contrast to studies with nicotine, no electrically induced activation of adrenergic nerves was obtained. To explain a similar difference in the colon, Stockley and Bennett (1974) suggested that adrenergic and non-adrenergic nerves might respond to different electrical stimuli. Bucknell $(1965,1966)$ found that frequencies above $8 \mathrm{~Hz}$ were required to stimulate adrenergic nerves in human taeniae. Furthermore, in preliminary experiments in colonic strips, it seems that adrenergic as well as non-adrenergic components of the relaxation can be demonstrated with $0.5 \mathrm{~ms}$ but not with $1 \mathrm{~ms}$ pulses (Stockley, 1974). The need for $2 \mathrm{~ms}$ pulses to elicit substantial contractions of human stomach strips, and the direct stimulation of the muscle at higher frequencies, might explain the absence of adrenergically-mediated responses in these experiments. Further studies using shorter pulses and a different electrode arrangement to avoid exciting the muscle directly (Bennett and Stockley, 1974) might reveal electrically induced adrenergic relaxations.

The unresponsiveness of the gastric body circular muscle does not seem to be due to a deficient cholinergic innervation, since many cholinesterasepositive nerves can be demonstrated histologically (Bennett and Stockley, 1973a). Perhaps the explanation lies in the anatomy of the gastric muscle layers. The gastric body consists of three muscle coats, of which the circular layer is central and therefore partly insulated from the electric impulses. The oblique muscle layer is absent in the antrum, so the circular muscle of this region, like the longitudinal muscle from both parts, is relatively exposed. Although the myenteric plexus is enclosed between two muscle layers in all cases, more current (longer pulses or higher frequency) might be needed to excite nerves supplying the circular muscle in the gastric body. The intrinsic innervation of human stomach appears broadly similar to that of the guinea-pig, kitten, rat and mouse. Isolated stomachs from these species respond to transmural stimulation with vigorous peristalsis (Armitage and Dean, 1966) or a strong cholinergic contraction followed by an afterrelaxation which appears to be adrenergic (Paton and Vane, 1963). In the guinea-pig, non-adrenergic inhibitory nerves appear to reach the stomach via the vagus nerves (Campbell, 1966a; Beani, Bianchi, and Crema, 1971).

In the ileum, the types of response seen during electrical stimulation in the absence of antagonists closely resembled those elicited with the ganglionstimulating drug dimethylphenylpiperazinium iodide (DMPP; Bennett, 1965). Cholinergic contractions usually predominated in the longitudinal muscle, but in the circular muscle they were at least partly masked by a strong inhibitory response. As in the stomach, the electrically induced relaxations seemed to be mediated by non-adrenergic nerves, whereas DMPP-induced relaxations appeared to involve adrenergic nerves. Using the same arguments as above, it seems that the ileum possesses both adrenergic and non-adrenergic inhibitory nerves, and that the nature of response elicited depends on the type of stimulation. The small, apparently noncholinergic, contractions observed at low frequencies in some strips resemble those seen in human oesophagus and colon. Except for the probable exclusion of 5-HT, no evidence has been obtained about the mediator of this response. Electrical transmural or field stimulation of other mammalian small intestine has also revealed mainly cholinergic excitatory responses in the longitudinal muscle (Munro, 1953; Paton, 1955; Day and Vane, 1963; Day and Warren, 1968; Drakontides and Gershon, 1968). Nervemediated non-cholinergic contractions have been observed also in the longitudinal muscle of guineapig ileum (Ambache and Freeman, 1968), where the main atropine-resistant contraction seems to be mediated by two uncharacterized spasmogens: one is released at $5 \mathrm{~Hz}$ and the other requires higher frequencies (Ambache, Verney, and Zar, 1970). It is not known if the contractions seen in human tissue are similar to these.

In contrast to human terminal ileum, contractions seem to predominate in guinea-pig ileal circular muscle. However, the apparent absence of inhibitory responses may be due to the lack of tone in 
these preparations. In the presence of hyoscine, the contraction during electrical stimulation is prevented and replaced by an after-contraction (Kottegoda, 1969) which might be a 'rebound' response following stimulation of inhibitory nerves.

THE CAUSES OF OTHER CONTRACTIONS IN HUMAN ALIMENTARY MUSCLE

Rapid after-contractions have been observed in many human oesophageal, ileal and colonic strips following inhibitory responses. Similar contractions have been recorded in response to intramural nerve stimulation in longitudinal and circular gut muscle preparations from a wide range of species, but they have not been found in stomach muscle. Campbell (1966b) suggested that these are 'rebound' contractions following stimulation of inhibitory nerves and hyperpolarization of the muscle. In support of this hypothesis Furness $(1970,1971)$ demonstrated that the 'rebound' excitation following stimulation of periarterial nerves to the guinea-pig colon was prevented by blocking the inhibitory response. Furthermore, removal of the hyperpolarizing effects of noradrenaline, ATP or a brief period of anoxia caused 'rebound' contractions even in the presence of tetrodotoxin.

The slow after-contractions which were observed in circular muscle strips from the ascending colon superficially resemble those recorded in guinea-pig colonic longitudinal muscle (Bennett and Fleshler, 1969, 1971; Costa and Furness, 1972; Furness and Costa, 1973). However, the transmitter of the human colonic circular muscle responses does not seem to be 5-HT as was proposed for the guinea-pig proximal colon (Furness and Costa, 1973). The transmitter in guinea-pig distal colon was thought not to be 5-HT, histamine or a sympathomimetic amine (Bennett and Fleshler, 1971).

\section{GRADIENTS OF INNERVATION IN THE GUT} AND THEIR RELATION TO MOTILITY

Figure 5 compares responses of different parts of the alimentary tract to electrical stimulation at $4 \mathrm{~Hz}$ in the absence of antagonists. There is a clear gradient of response from the stomach to colon in the longitudinal muscle, with excitation dominant proximally and inhibition dominant distally. In the circular muscle the picture is slightly different: the inhibition was poor in the stomach and seemed to be greater in the terminal ileum than in the colon. However, since the type of response elicited appears to vary with the stimulating frequency (the proportion of strips contracting is generally increased at frequencies above or below $4 \mathrm{~Hz}$ ), the extent of the intestinal gradient in vivo at any particular time would depend on the relative rates of firing in the different types of intrinsic nerve. Since frequencies up to about $10 \mathrm{~Hz}$ are considered to be physiological, a wide range of responses would be possible. The circular oesophageal and ileal strips relaxed more often than the longitudinal muscle from these regions, whereas in the sigmoid colon the proportion relaxing was greater in the longitudinal than in the circular strips. This distinction might relate to function, since the oesophagus and ileum are propulsive organs whereas the colon acts mainly as a store. The results of the present study confirm the finding (Bennett and Whitney, 1966a) that there is a transition down the gut from predominant cholinergic excitatory innervation proximally to mainly inhibitory innervation in the colon: intrinsic cholinergic activity is dominant in highly motile regions and vice versa. It is not known to what extent regional differences in the distribution of intrinsic nerves, their sensitivity to stimulation, regional variations in tone or in the responsiveness to transmitters affect the tendency to contract or relax. The latter possibility seems unlikely to be the sole explanation, since the effects of ganglion stimulants differ in jejunum and ileum although the responsiveness to acetylcholine and adrenaline is similar (Bennett and Whitney, 1966a).

Regional differences in the intrinsic innervation therefore probably contribute to variations in motility patterns. However, this is only one aspect of the way that gut movements are regulated. Myogenic contractions, extrinsic nerves and hormones are also important. As with the intrinsic innervation, gradients have been reported in rates of myogenic contractions in the stomach and small intestine (Alvarez, 1948). Rhythmic electrical activity throughout the gut is considered to be a fundamental mechanism in the control of motility (Daniel, 1973). There are regional differences in rhythmicity and rate of propagation of this 'control electrical activity' (Bass, 1968; Daniel and Irwin, 1968; Gillespie, 1968; Prosser and Bortoff, 1968; Daniel, 1973), varying in dogs from about $11 /$ min near the gastric cardia to 4.8 to $6 / \mathrm{min}$ in the body of the stomach, 1 to $2 / \mathrm{min}$ in the antrum, 17 to $18 / \mathrm{min}$ in the duodenum and $12.5 / \mathrm{min}$ near the caecum. Studies in human subjects suggest similar relations (see Daniel, 1973). Rates of colonic slow waves differ between species. In the cat colon the frequency increases distally, but the gradient is small and frequently reverses (Christensen, 1971).

The slow waves seem incapable of eliciting contractions directly, but spikes which may be triggered by slow waves are coupled to the contractile mechanism (Prosser and Bortoff, 1968). The waves may be directly related to metabolic activity since their frequency is very sensitive to temperature 
changes and metabolic inhibitors, and a steep aboral gradient in $\mathrm{O}_{2}$ consumption in cat isolated small intestine has been demonstrated (Dorman and Steggerda, 1961).

The extrinsic innervation of the gut consists of vagal and sacral parasympathetic nerves, and sympathetic fibres from the thoracic and lumbar outflows with synapses in the mesenteric ganglia. The distribution of vagal efferent endings varies in different regions of the gastrointestinal tract, with more fibres passing to the stomach than to the intestines (Kosterlitz, 1968). There are some nonadrenergic fibres in the vagus which mediate receptive relaxation of the stomach (Jansson, 1969). The numerous extrinsic nerves in the stomach, compared to the relatively weak intrinsic innervation as judged by responses to electrical stimulation, suggest that gastric motility is controlled to a large extent by extrinsic nerves. This correlates with the gastric stasis which occurs after vagotomy. By contrast, intestinal activity is regulated predominantly by intrinsic nerves. The sacral parasympathetic nerves to the pelvic colon are required for defaecation (Mendeloff, 1968), but in more proximal regions of the intestine the influence of extrinsic parasympathetic nerves appears slight (Gillespie, 1968; Kosterlitz, 1968). Sympathetic nerves reach all regions of the gastrointestinal tract but under normal conditions they may contribute little to the control of motility (Celander, 1959).

Although gut motility may also be affected by locally released substances or circulating hormones, such as prostaglandins, substance $P$ and gastrin, electrical slow wave activity and the intrinsic innervation seem to be fundamental for the control of normal gut activity. Both show gradients down the gut which relate to regional differences in function. The mechanisms interact since action potentials occur only at the peak of the slow waves. However, it remains to be seen whether the intrinsic nerves can influence the rate and coupling of slow waves (see Daniel, 1973) as well as altering the muscle membrane potential.

We are grateful to Dr J. E. Pike, UpJohn Ltd, USA, for $\mathrm{PGE}_{2}$, and the Wellcome Trust for support (HLS).

\section{References}

Alvarez, W. C. (1948). An Introduction to Gastro-enterology, 4th ed. Heinemann, London.

Ambache, N., and Freeman, M. A. (1968). Atropine-resistant longitudinal muscle spasms due to excitation of non-cholinergic neurones in Auerbach's plexus. J. Physiol. (Lond.), 199, 705-727.

Ambache, N., Verney, J., and Aboo Zar, M. (1970). Evidence for the release of two atropine-resistant spasmogens from Auerbach's plexus. J. Physiol. (Lond.), 207, 761-782.

Armitage, A. K., and Dean, A. C. B. (1966). The effects of pressure and pharmacologically active substances on gastric peristalsis in a transmurally stimulated rat stomach-duodenum preparation. J. Physiol. (Lond.), 182, 42-56.

Bass, P. (1968). In vivo electrical activity of the small bowel In Handbook of Physiology, Sect. 6, edited by C. F. Code, Vol. 4, pp. 2051-2074. American Physiological Society, Washington, D.C.

Beani, L., Bianchi, C., and Crema, A. (1971). Vagal non-adrenergic inhibition of guinea-pig stomach. J. Physiol. (Lond.), 217, 259 279.

Bennett, A. (1964). An improved isolated organ bath. J. Sci. Technol., 10, 176-177.

Bennett, A. (1965). A pharmacological investigation of human isolated ileum. Nature (Lond.), 208, 1289-1291.

Bennett, A. (1968). Relationship between in vitro studies of gastrointestinal muscle and motility of the alimentary tract in vivo. Amer. J. dig. Dis., 13, 410-414.

Bennett, A. (1970). Control of gastrointestinal motility by substances occurring in the gut wall. Rendic rom. Gastro-ent., 2, 133-142.

Bennett, A., and Fleshler, B. (1969). A hyoscine resistant excitatory nerve pathway in guinea-pig colon. J. Physiol. (Lond.), 203, 62P-63P.

Bennett, A., and Fleshler, B. (1971). A noncholinergic excitatory nerve pathway in guinea-pig colon. Amer. J. dig. Dis., 16, 550551 .

Bennett, A., and Stockley, H. L. (1973a). A study of the intrinsic innervation of human isolated gastrointestinal muscle using electrical stimulation. J. Physiol. (Lond.), 233, 34P-35P.

Bennett, A., and Stockley, H. L. (1973b). Electrically induced contractions of guinea-pig isolated ileum resistant to tetrodotoxin. Brit. J. Pharmacol., 48, 359P-360P.

Bennett, A., and Stockley, H. L. (1974). Effect of electrode positions on contractions of guinea-pig isolated ileum to electrical stimulation. Brit. J. Pharmacol., 50, 453P-454P.

Bennett, A., and Whitney, B. (1966a). A pharmacological study of the motility of the human gastrointestinal tract. Gut, 7, 307-316.

Bennett, A., and Whitney, B. (1966b). A pharmacological investigation of human isolated stomach. Brit. J. Pharmacol., 27, 286298.

Bucknell, A. (1965). Effects of direct and indirect stimulation on isolated colon. J. Physiol. (Lond.), 177, 58P-59P.

Bucknell, A. (1966). Studies of the physiology and pharmacology of the colon of man and other mammals. PhD Thesis, University of London.

Bucknell, A., and Whitney, B. (1964). A preliminary investigation of the pharmacology of the human isolated taenia coli preparation. Brit. J. Pharmacol., 23, 164-175.

Burnstock, G. (1972). Purinergic nerves. Pharmacol. Rev., 24, 509-581.

Burnstock, G., Campbell, G., Satchell, D., and Smythe, A. (1970). Evidence that adenosine triphosphate or a related nucleotide is the transmitter substance released by non-adrenergic inhibitory nerves in the gut. Brit. J. Pharmacol., 40, 668-688.

Burnstock, G., Satchell, D. C., and Smythe, A. (1972). A comparison of the excitatory and inhibitory effects of non-adrenergic, non-cholinergic nerve stimulation and exogenously applied ATP on a variety of smooth muscle preparations from different vertebrate species. Brit. J. Pharmacol., 46, 234-242.

Campbell, G. (1966a). The inhibitory nerve fibres in the vagal supply to the guinea-pig stomach. J. Physiol. (Lond.), 185, 600-612.

Campbell, G. (1966b). Nerve-mediated excitation of the taenia of the guinea-pig caecum. J. Physiol. (Lond.), 185, 148-159.

Celander, O. (1959). Are there any centrally controlled sympathetic inhibitory fibres to the musculature of the intestine. Acta physiol. scand., 47, 299-309.

Christensen, J. (1970). Patterns and origin of some esophageal responses to stretch and electrical stimulation. Gastroenterology, 59, 909-916.

Christensen, J. (1971). The controls of gastrointestinal movements: some old and new views. New Engl. J. Med., 285, 85-98.

Costa, M., and Furness, J. B. (1972). Slow contraction of the guineapig proximal colon in response to the stimulation of an unidentified type of nerve. Brit. J. Pharmacol., 45, 151P-152P.

Crema, A., del Tacca, M., Frigo, G. M., and Lecchini, S. (1968). Presence of a non-adrenergic inhibitory system in the human colon. Gut, 9, 633-637.

Daniel, E. E. (1973). A conceptual analysis of the pharmacology of gastrointestinal motility. In International Encyclopedia of Pharmacology and Therapeutics, Sect. 39A: Pharmacology of Gastrointestinal Motility and Secretion, edited by P. Holton, Vol. 2, pp. 457-545. 
Daniel, E. E., and Irwin, J. (1968). Electrical activity of gastric musculature. In Handbook of Physiology, Sect. 6, edited by C. F. Code, Vol. 4, pp. 1969-1984. American Physiological Society, Washington, D.C.

Day, M., and Vane, J. R. (1963). An analysis of the direct and indirect actions of drugs on the isolated guinea-pig ileum. Brit. $J$. Pharmacol., 20, 150-170.

Day, M. D., and Warren, P. R. (1968). A pharmacological analysis of the responses to transmural stimulation in isolated intestinal preparations. Brit. J. Pharmacol., 32, 227-240.

Dorman, H. L., and Steggerda, F. R. (1961). Characterization of the metabolic gradient in cat small intestine by layer fractionation. Amer. J. Physiol., 201, 292-294.

Douglas, W. W., and Ritchie, J. M. (1957). On the frequency of firing of mammalian non-medullated nerve fibres. J. Physiol. (Lond.) $139,400-407$.

Drakontides, A. B., and Gershon, M. D. (1968). 5-hydroxytryptamine receptors in the mouse duodenum. Brit. J. Pharmacol., 33, 480-492.

Ellis, F. G., Kauntze, R., Nightingale, A., and Trounce, J. R. (1960). Further studies in achalasia of the cardia. Quart. J. Med., 29, 305-312.

Fishlock, D. J., and Parks, A. G. (1963a). A study of human colonic muscle in vitro. Brit. med. J., 2, 666-667.

Fishlock, D. J., and Parks, A. G. (1963b). Nicotine and colonic muscle. (Letter) Brit. med. J., 2, 1528.

Fishlock, D. J., and Parks, A. G. (1966). The action of nicotine on the circular muscle of the human ileum and colon in vitro. Brit. $J$. Pharmacol., 26, 79-86.

Folkow, B. (1952). Impulse frequency in sympathetic vasomotor fibres correlated to the release and elimination of the transmitter. Acta physiol. scand., 25, 49-76.

Furness, J. B. (1970). An examination of nerve-mediated, hyoscineresistant excitation of the guinea-pig colon. J. Physiol. (Lond.), 207, 803-821.

Furness, J. B. (1971). Secondary excitation of intestinal smooth muscle. Brit. J. Pharmacol., 41, 213-226.

Furness, J. B., and Costa, M. (1973). The nervous release and the action of substances which affect intestinal muscle through neither adrenoceptors nor cholinoreceptors. Phil. Trans. $R$. Soc. B., 265, 123-133.

Gillespie, J. S. (1968). Flectrical activity in the colon. In Handbook of Physiology, Sect. 6, edited by C. F. Code, Vol. 4, pp. 2093-2120. American Physiological Society, Washington, D.C.

Haffner, J. F. W., Liavag, I., and Setekleiv, J. (1969). Excitatory adrenergic receptors in the human stomach and pylorus. Scand. J. Gastroent., 4, 145-150.

Jansson, G. (1969). Vago-vagal reflex relaxation of the stomach in the cat. Acta Physiol. scand., 75, 245-252.
Kao, C. Y. (1966). Tetrodotoxin, saxitoxin and their significance in the study of excitation phenomena. Pharmacol. Rev., 18, 997 1049.

Kosterlitz, H. W. (1968). Intrinsic and extrinsic nervous control of motility of the stomach and the intestines. In Handbook of Physiology, Sect. 6, edited by C. F. Code, Vol.4, pp. 2147-2172. American Physiological Society, Washington, D.C.

Kottegoda, S. R. (1969). An analysis of possible nervous mechanisms involved in the peristaltic reflex. J. Physiol. (Lond.), 200, 687. 712.

Lund, G. F., and Christensen, J. (1969). Electrical stimulation of esophageal smooth muscle and effects of antagonists. Amer. $J$. Physiol., 217, 1369-1374.

Mendeloff, A. I. (1968). Defaecation. In Handbook of Physiology Sect. 6, edited by C. F. Code, Vol. 4, pp. 2140-2146. American Physiological Society, Washington, D. C.

Metcalfe, H. L., and Bennett, A. (1971). The intrinsic innervation of the human stomach. Rendic rom. Gastro-ent., 3, 132-133.

Misiewicz, J. J., Waller, S. L., Anthony, P. P., and Gummer, J. W. P. (1969). Achalasia of the cardia: pharmacology and histopathology of isolated cardiac sphincteric muscle from patients with and without achalasia. Quart. J. Med., 38, 17-30.

Munro, A. F. (1953). Effect of autonomic drugs on the responses of isolated preparations from the guinea-pig intestine to electrical stimulation. J. Physiol. (Lond.), 120, 41-52.

Paton, W. D. M. (1955). The response of the guinea-pig ileum to electrical stimulation by coaxial electrodes. J. Physiol. (Lond.) 127, 40P-41P.

Paton, W. D. M., and Vane, J. R. (1963). An analysis of the responses of the isolated stomach to electrical stimulation and to drugs. J. Phvsiol. (Lond.), 165, 10-46.

Prosser, C. L., and Bortoff, A. (1968). Electrical activity of intestinal muscle under in vitro conditions. In Handbook of Physiology, Sect. 6, edited by C. F. Code, Vol. 4, pp. 2025-2050. American Physiological Society, Washington, D.C.

Stockley, H. L. (1974). Pharmacological studies on the innervation of human and guinea-pig isolated alimentary smooth muscle. PhD Thesis, University of London.

Stockley, H. L., and Bennett, A. (1974). The intrinsic innervation of human sigmoid colonic muscle. In Proceedings of the IVth International Symposium on Gastrointestinal Motility, edited by E. E. Daniel, pp.165-176. Mitchell Press, Vancouver.

Tuch, A., and Cohen, S. (1973). Lower esophageal sphincter relaxation: studies on the neurogenic inhibitory mechanism. $J$. clin. Invest., 52, 14-20.

Whitney, B. (1965). A preliminary investigation of the pharmacology of longitudinal muscle strips from human isolated jejunum. J. Pharm. Pharmacol., 17, 465-473. 